\title{
A proposal for a postoperative protocol for the early diagnosis of bronchopleural fistula after lung resection surgery
}

\author{
Luca Bertolaccini $^{1} \wedge$, Elena Prisciandaro ${ }^{1}$, Juliana Guarize $^{2}$, Lorenzo Spaggiari $^{1,3}$ \\ ${ }^{1}$ Department of Thoracic Surgery, IEO, European Institute of Oncology IRCCS, Milan, Italy; ${ }^{2}$ Interventional Pneumology Unit, IEO, European \\ Institute of Oncology IRCCS, Milan, Italy; ${ }^{3}$ Department of Oncology and Hemato-Oncology, University of Milan, Milan, Italy \\ Correspondence to: Luca Bertolaccini, MD, PhD, FCCP. Division of Thoracic Surgery, IEO, European Institute of Oncology IRCCS, Via Ripamonti \\ 435, 20141 Milan, Italy. Email: luca.bertolaccini@gmail.com.
}

Submitted Jul 03, 2021. Accepted for publication Aug 25, 2021.

doi: $10.21037 /$ jtd-21-1095

View this article at: https://dx.doi.org/10.21037/jtd-21-1095

\section{Introduction}

Bronchopleural fistula (BPF) is a potentially catastrophic complication of lung surgery (pneumonectomy, lobectomy, segmentectomy) (1) and represents a non-negligible cause of readmission during the first postoperative year (2). BPFs usually occur within three months after surgery, and based on their onset, they are classified as: early (1-7 days), intermediate ( $8-30$ days), and late ( $>30$ days) (3). When diagnosed within the first postoperative week, the BPF is likely secondary to a mechanical failure of bronchial stump closure and requires surgical re-exploration. Intermediate $\mathrm{BPF}$ are primarily related to infections and are not rare in immunosuppressed or debilitated patients with multiple comorbidities; subacute presentations are more insidious and characterised by wasting, malaise, and fever. Late BPFs are also associated with pleural cavity infection and fibrosis.

According to an analysis of the European Society of Thoracic Surgery (ESTS) database, the overall incidence of $\mathrm{BPF}$ in lung resection surgery is $1.9 \%$ (4), with a frequency ranging from $4.5 \%$ to $20 \%$ after pneumonectomies and from $0.5 \%$ to $1 \%$ after lobectomies (5). Other published statistics indicate that the BPF incidence is $<1 \%$ following lobectomy and sublobar resection, and between $4 \%$ and $20 \%$ following pneumonectomy (6). The mortality related to the adverse effects of BPF ranges from $18 \%$ to $50 \%$. The most common risk factors of BPF include right-sided pneumonectomy, neoadjuvant therapy, and right lower lobectomy (7).
The BPF is commonly detected on the caudal extremity of the bronchial stump due to the increased risk of ischemic necrosis and/or to the pooling of secretions leading to bacterial overgrowth and colonisation $(1,8)$.

Although several studies have aimed at predicting the occurrence $(9,10)$ and establishing a management strategy for BPF (11), to date, there are no published consensus statements or recommendations that guide surgical practice. Fibreoptic bronchoscopy appears more advantageous than other clinical and radiological approaches for diagnosing BPF. It also allows proper evaluation of the stump, direct localisation of the orifice, and the introduction of sealants into the fistulous tract (12). It is also a fundamental tool in the sequential monitoring of chronic BPF.

Based on our experience with postoperative BPFs and their bronchoscopic follow-up $(11,13,14)$, we propose a postoperative protocol for the early identification of fistulas after pneumonectomies and sleeve lobectomies.

\section{Postoperative protocol}

All the patients who undergo a pneumonectomy or a sleeve lobectomy are scheduled for follow-up visits as follows:

* One month after surgery: physical examination, chest $\mathrm{X}$-ray and blood tests.

* Every six months for three years: physical examination and chest and upper abdomen computed tomography (CT).

^ ORCID: 0000-0002-1153-3334. 
Table 1 Clinical bronchoscopic classification of the bronchial stump in pneumonectomies and sleeve lobectomies

\begin{tabular}{lll}
\hline Grade & After pneumonectomy & After sleeve lobectomy \\
\hline 0 & Regular bronchial stump & Regular bronchial stump \\
1 & $\begin{array}{l}\text { Little irregularity of the suture line (visualisation of the } \\
\text { inner suture line) }\end{array}$ & Haematoma of the suture line with fibrin deposition \\
2 & Little irregularity of the suture line with haematoma & Little area of necrosis of the suture line without clinical signs of BPF \\
3 & $\begin{array}{l}\text { (I) Little continuity solution without clinical signs of BPF; } \\
\text { (II) Dead-end micro-BPF }\end{array}$ & Seamless suture line without clinical signs of BPF \\
4 & BPF with clinical signs ( $\leq 1 / 3$ suture) & BPF with clinical signs ( $\leq 1 / 3$ suture) \\
5 & Complete BPF $(>1 / 3$ suture) & Complete BPF $(>1 / 3$ suture)
\end{tabular}

BPF, bronchopleural fistula.

* Every year (after postoperative year three and up to five years), physical examination and chest and upper abdomen CT.

A bronchoscopic follow-up is conducted with three fibreoptic bronchoscopies:

* At time 0: on postoperative day 7 .

- At time +1:1 month after discharge as an outpatient modality.

- At time +3: 3 months after discharge as an outpatient modality.

If a BPF is detected, a clinical bronchoscopic classification of the lesions of the bronchial stump is employed (Table 1). The initial grade of BPF may allow bronchoscopic interventions. Quick operative intervention, significantly when the BPF is early diagnosed, with transthoracic stump revision or open window thoracostomy may eventually accelerate BPF closure and improve survival. This postoperative protocol is still ongoing.

\section{Comments}

An alveolar-pleural fistula or air leak is the most frequent postoperative complication following elective lung resection. An air leak is described as the communication of the pulmonary parenchyma's alveoli with the pleural space distal to a segmental bronchus. As defined by the Society of Thoracic Surgeons General Thoracic Surgery Database, a protracted air leak persists beyond five days postoperatively. In contrast to alveolar-pleural fistulae, a BPF connects the main stem, lobar, or sublobar bronchus and the pleural area (6). BPF represents a thorny, longstanding issue for thoracic surgeons. Prevention measures are not always successful, and management approaches are controversial, even unorthodox at times. BPF has a detrimental effect on other perioperative outcomes, as these patients' duration of stay is dramatically increased, resulting in a $30 \%$ rise in inpatient costs (6).

As previously reported, our BPF protocol is based on a time-dependent algorithm. Namely, symptomatic patients are started on antibiotics and undergo double chest tube placement for pleural irrigation immediately after the radiological or endoscopic diagnosis of BPF. Subsequently, direct surgical repair is attempted in early (less than two weeks after surgery) BPF patients. At the same time, bronchoscopic procedures are performed in late, small BPF cases, leaving open window thoracostomy as a last resort (11).

Paradoxically, the lack of symptoms complicates matters, as early detection of asymptomatic BPF is usually fortuitous, and surgeons are faced with a management dilemma: to treat or not to treat? On the one hand, a cautious waitand-watch attitude would seem advisable to spare a patient in good clinical status further invasive manoeuvres or even a morbid open-window thoracostomy. On the other hand, a prompt therapeutic response might prevent the enlargement of the orifice and the onset of empyema.

We are also aware of the possibility to not achieve the necessary results due to the low incidence of BPF. Perhaps a more stratified approach would be more cost-effective. Predictors for BPF could be obtained from the ESTS database and stratify patients at higher risk for development of BPF (4).

Nonetheless, bronchoscopy is a practical examination but also is an invasive procedure. Routine bronchoscopy plays a crucial role in the postoperative surveillance of pneumonectomies or sleeve lobectomies. A minimally 
invasive technique enables the operator to inspect the trachea-bronchial mucosa, check the vocal folds for paralysis, and the bronchial stump for BPF or tumour recurrence. Above all, in the case of BPF, sequential bronchoscopies allow a comparative measurement of the size of the orifice to determine whether it is healing, thus guiding subsequent therapeutic decisions.

Nevertheless, a randomised controlled study with patients randomised to this protocol $v s$. no serial bronchoscopies will be needed. An evaluation of the proposed protocol and needed number to treat to identify one BPF that would have been otherwise missed will be more critical for surgeons.

\section{Conclusions}

In conclusion, our follow-up protocol for postoperative BPF prevention and early diagnosis with sequential bronchoscopy allows early detection and close monitoring of the fistula, thus ensuring the surgeon more freedom to decide whether and when to treat. Besides, systematic bronchial stump coverage is fundamental not only for preventing BPF but also for limiting the enlargement and communication with the residual cavity.

\section{Acknowledgments}

Funding: This work was partially supported by the Italian Ministry of Health with Ricerca Corrente and $5 \times 1000$ funds.

\section{Footnote}

Provenance and Peer Review: This article was a standard submission to the journal. The article has undergone external peer review.

Conflicts of Interest: All authors have completed the ICMJE uniform disclosure form (available at https://dx.doi. org/10.21037/jtd-21-1095). LB serves as an unpaid editorial board member of Fournal of Thoracic Disease from January 2016 to December 2021. The other authors have no conflicts of interest to declare.

Ethical Statement: The authors are accountable for all aspects of the work in ensuring that questions related to the accuracy or integrity of any part of the work are appropriately investigated and resolved.
Open Access Statement: This is an Open Access article distributed in accordance with the Creative Commons Attribution-NonCommercial-NoDerivs 4.0 International License (CC BY-NC-ND 4.0), which permits the noncommercial replication and distribution of the article with the strict proviso that no changes or edits are made and the original work is properly cited (including links to both the formal publication through the relevant DOI and the license). See: https://creativecommons.org/licenses/by-nc-nd/4.0/.

\section{References}

1. Gaur P, Dunne R, Colson YL, et al. Bronchopleural fistula and the role of contemporary imaging. J Thorac Cardiovasc Surg 2014;148:341-7.

2. Jones GD, Caso R, No JS, et al. Prognostic factors following complete resection of non-superior sulcus lung cancer invading the chest wall. Eur J Cardiothorac Surg 2020;58:78-85.

3. Varoli F, Roviaro G, Grignani F, et al. Endoscopic treatment of bronchopleural fistulas. Ann Thorac Surg 1998;65:807-9.

4. Brunelli A, Rocco G, Szanto Z, et al. Morbidity and mortality of lobectomy or pneumonectomy after neoadjuvant treatment: an analysis from the ESTS database. Eur J Cardiothorac Surg 2020;57:740-6.

5. Di Maio M, Perrone F, Deschamps C, et al. A metaanalysis of the impact of bronchial stump coverage on the risk of bronchopleural fistula after pneumonectomy. Eur J Cardiothorac Surg 2015;48:196-200.

6. Clark JM, Cooke DT, Brown LM. Management of Complications After Lung Resection: Prolonged Air Leak and Bronchopleural Fistula. Thorac Surg Clin 2020;30:347-58.

7. Li S, Fan J, Liu J, et al. Neoadjuvant therapy and risk of bronchopleural fistula after lung cancer surgery: a systematic meta-analysis of 14912 patients. Jpn J Clin Oncol 2016;46:534-46.

8. Okuda M, Go T, Yokomise H. Risk factor of bronchopleural fistula after general thoracic surgery: review article. Gen Thorac Cardiovasc Surg 2017;65:679-85.

9. Pforr A, Pagès PB, Baste JM, et al. A Predictive Score for Bronchopleural Fistula Established Using the French Database Epithor. Ann Thorac Surg 2016;101:287-93.

10. Mammana M, Marulli G, Zuin A, et al. Postpneumonectomy bronchopleural fistula: analysis of risk factors and the role of bronchial stump coverage. Surg 
Today 2020;50:114-22.

11. Mazzella A, Pardolesi A, Maisonneuve P, et al. Bronchopleural Fistula After Pneumonectomy: Risk Factors and Management, Focusing on Open-Window Thoracostomy. Semin Thorac Cardiovasc Surg 2018;30:104-13.

12. Li S, Fan J, Zhou J, et al. Residual disease at the bronchial stump is positively associated with the risk of bronchoplerual fistula in patients undergoing lung cancer

Cite this article as: Bertolaccini L, Prisciandaro E, Guarize J, Spaggiari L. A proposal for a postoperative protocol for the early diagnosis of bronchopleural fistula after lung resection surgery. J Thorac Dis 2021;13(11):6495-6498. doi: 10.21037/jtd21-1095 surgery: a meta-analysis. Interact Cardiovasc Thorac Surg 2016;22:327-35.

13. Grunenwald D, Spaggiari L. Technique for early bronchopleural fistula repair after lung resection. Ann Thorac Surg 1997;63:1214-5.

14. Leo F, Solli P, Veronesi G, et al. Review on bronchopleural fistula: did a surgeon review it? Chest 2006;129:1731; author reply 1731-2; discussion 1732 . 